\title{
LAST RESORT GAMBLES, RISKY DEBT AND LIQUIDATION POLICY*
}

\author{
Elettra Agliardi ${ }^{1}$, Rainer Andergassen $^{2 \dagger}$ \\ Department of Economics, University of Bologna \\ P.zza Scaravilli 2, 40126 Bologna, Italy \\ ${ }^{1}$ E-mail: agliardi@economia.unibo.it \\ ${ }^{2}$ E-mail: anderga@economia.unibo.it
}

November, 2006

\begin{abstract}
This paper develops a real option model in which the interaction between debt, liquidation policy and risky investments is studied. We consider a manager who owns the firm and faces the opportunity to invest in risky projects which boost current profits at the cost of bankruptcy if they turn out to be unsuccessful. These investments are "last resort gambles" in the sense that, if successful, they save the company from insolvency, while, if unsuccessful, they make liquidation unavoidable. We show that last resort gamble strategies boost the company's value, delaying liquidation. We study how the liquidation and the last resort gamble strategies are affected by the firm's capital structure.
\end{abstract}

KEYWORDS: Last resort gambles; risky investments; liquidation policy; real options.

JEL: $\quad$ G30

\footnotetext{
*The authors acknowledge financial support from the Polo Scientifico Didattico, Rimini. A previous version of this paper has been presented at the 30th Anniversary of the JBF Conference, Peking University, 2006, at the 10th International Conference on Real Options, Columbia University, New York, 2006 and at the 1st International Conference on Small Open Economies in a Globalized World,University of Bologna, 2006. The authors are grateful to the participants for their comments and, in particular, they thank Giuseppe Bertola and Gordon Sick for their invaluable suggestions.
}

${ }^{\dagger}$ Corresponding author. Tel.: +390512098666, Fax: +390512098040. 


\section{Introduction}

In a situation of financial distress, managers, acting as rational economic agents trying to resurrect their company, may end up engaging in "last resort gambles", that is, they employ an investment strategy that, if successful, would save the company from insolvency, if unsuccessful, would make liquidation unavoidable. On the verge of bankruptcy managers employ this strategy with the aim to "weather out the storm", that is, they invest in risky projects trying to bridge bad and good times.

In this context it is often difficult to ascertain whether real investment are incurred with the objective to manipulate earnings or just for strategic considerations. Failures at Enron, WorldCom and Tyco in the US together with some other prominent companies in Europe (Vivendi, Ahold, Adecco, Parmalat, etc.) are iconic examples of corporate scandals combined with excessive risk taking which is influenced by moral hazard in the hopes of extraordinary returns that could rescue a company from bankruptcy (Lev, 2003; Jensen, 2005).

In this paper we consider a manager who owns the firm and faces the opportunity to invest in a risky project yielding a given amount of cash flow at the expense of liquidation in case of failure. This particular form of risk-taking may be interpreted as a sort of "last resort gamble", in that the firm delays the closure betting on a market upturn. We characterize the firm's optimal liquidation policy and optimal gambling strategy, showing reluctance of the manager to shut the company down. In this paper we abstract from agency problems arising from a conflict between managers and equity-holders and analyze a model where the management owns the firm and where a principal/agent problem eventually arises between debt-holders and the firm. Conflicts between debt-holders and equity-holders may arise because of the equity-holders incentive to invest in risky but poor projects, affecting the value of the debt. In this framework we study the impact of leverage on the optimal liquidation policy and how capital structure and bankruptcy decisions are affected by the investment strategy. 
The problem we tackle in this paper is closely related to the literature on moral hazard and excessive risk-taking, for which many colorful descriptions have been used, namely "gambling for resurrection", "heads I win, tails I break even", "fourth-quarter football", etc. (Hart, 2000; Akerlof and Romer, 1994).

Our paper is closely aligned with the literature on excessive continuation induced by equityholders' limited liability when a moral hazard problem arises between equity- and debt-holders. Knot and Vychodil (2006) examine debt contracting in the case of gambling for resurrection under different bankruptcy regimes. They show that under the absolute priority rule (such that nothing can be paid to a class of claimholders unless the claims of all superior classes are satisfied) equityholders tend toward excessive risk-taking and delaying bankruptcy filing; in contrast, a softer law or the possibility of creditors' verification of the firm's situation mitigate the problem of avoiding bankruptcy and represent an alternative solution to the gambling for resurrection problem. Decamps and Faure-Grimaud (2002), using a compound exchange option model, study a setting where excessive continuation always occur and such excessive continuation is even exacerbated as debt repayment increases. In our paper excessive continuation results from the last resort gamble strategy employed by the manager. We find excessive continuation both in the all-equity firm and in the case where an agency problem between equity- and debt-holders may arise.

The issue we address is linked to the asset substitution problem (see for example Leland, 1998), where the equity-holders face the option to switch to a riskier portfolio. This action leads to a delay in liquidation and excessive continuation. In particular, in Leland (1998) a firm can choose between two exogenous levels of the volatility of its value. In the leveraged case, it is shown that the choice which is optimal before issuing debt is not the same after debt has been issued. Our problem is similar to asset substitution in the sense that the manager switches to a riskier project with his last resort gamble strategy. In the case of asset substitution equity-holders benefit from an increased upside volatility by engaging in riskier project. In our case the last resort gamble strategy does not modify the upside volatility but equity-holders benefit from increased current 
cash flows at the cost of an increased downside volatility. In our paper analytical results are obtained, while in Leland (1998) results are obtained through numerical simulations.

Excessive risk-taking and bankruptcy postponing tendency of managers are often inextricably linked with a tendency of the management to misreporting. In some cases gambling for resurrection involves unlawful risk-taking, which means that it is a complementary strategy to earnings manipulation and corporate fraud ${ }^{1}$. When faced with the threat of firing, liquidation or in order to increase the value of stock options, managers are encouraged to take substantial risk and to boost short term profit through legal and sometimes fraudulent means. In some cases (see Johnson, Ryan and Tian, 2006) executives commit fraud to avoid under-performance resulting from significant slowdowns in their earnings growth, so that frauds are committed more likely during industry downturns.

Research on the determinants of fraud has indicated external financial needs (Povel et al., 2004), proximity to debt covenant violations and executive compensation as the main causes for violations of accounting principles and earnings manipulation. A few recent papers have examined the relation between executive equity-based compensation and corporate fraud (Goldman and Slezak, 2006; Burns and Kedia, 2006; Bergstresser and Philippon, 2006; Gao and Shrieves, 2002; Bebchuk, and Fried, 2003; Johnson, Ryan and Tian, 2006; Erickson,Hanlon and Maydew, 2006), and have emphasized that executives at fraud firms have significantly large equity-based compensation and greater financial incentives to commit fraud than executives at non-fraud firms. Anecdotal evidence suggests that analysts, investors and financial markets commentators often focus on firms' abilities to consistently increase earnings per share. A few papers have highlighted how earnings manipulation is not directly linked to an agency problem between managers and equity-holders (Bolton, Scheinkman and Xiong, 2003, 2005; Friebel and Guriev, 2005), and have found that top-management and initial shareholders have often aligned interests in over-reporting

\footnotetext{
1 Earnings manipulation has been discussed in several papers, among them we recall Stein (1989), Narayanan (1985) and Von Thadden (1995).
} 
short-term earnings, because they can sell stocks at higher prices to uninformed outside investors who base their evaluations on the accounting reports.

We study how last resort gambles influence liquidation policy and the interaction between the firm's financial structure, gambling and closure decisions. We use real option analysis to address the problem of optimal liquidation and gambling decisions. In Section 2 we study the value of the firm, if the firm faces the option of investing in a risky project which boosts current profits at the cost of liquidation, if the project fails. We find that engaging in this gamble is optimal in a market downturn: it increases the firm's value and affects the firm's closure policy, delaying liquidation. Thus, in engaging in a last resort gamble, the firm bets on a market upturn, trying to bridge good and bad times. In Section 3 we extend the basic setting to the case where the firm is financed by issuing debt and equity and where it must pay interest to its creditors continuously and bankruptcy is triggered by default on this payment. We derive the equity-holders and debtholders claims and study how the firm's financial structure influences optimal liquidation and gambling policies. Last resort gambling boosts the equity value, inducing a delay in liquidation. Furthermore, we find that increasing the firm's indebtedness speeds up liquidation. Debt financing mitigates the conflict between share- and debt-holders because debt service reduces the amount of free cash flows available to equity-holders. A larger indebtedness reduces the equity-holders' gains from a last resort gamble, reducing the appeal of such a strategy. We find a threshold level for the debt above which engaging in last resort gambling is never optimal. We compare the debt value in the case of a last resort gamble and in the case where a last resort gamble is not available. We show that the difference between the two debt values depends on the coupon value; in particular, as the coupon value increases, the distortions induced by a last resort gamble decrease, making such difference more likely to be positive. Section 4 generalizes the model to the scenario where different degrees of gambling intensities are possible. While in Section 3 the firm can choose between engaging in a last resort gamble or not, in Section 4 we introduce a choice between different gambling intensities. We find that as the firm's indebtedness increases, gambling 
intensity decreases. Section 5 contains the conclusion and final remarks.

\section{The model}

A firm generates total operating profits of $K x_{t}-f$, where $f$ is a fixed cost, $K$ is a constant parameter, $x_{t}$ a geometric Brownian motion representing exogenous demand shocks

$$
d x_{t}=\mu x_{t} d t+\sigma x_{t} d B_{t}
$$

$\mu$ is a drift term and $\sigma$ measures volatility. As $x$ falls, the firm faces the opportunity to close the activity irreversibly and is left with a constant liquidation value. Let $H$ be the constant liquidation value of the firm net of bankruptcy costs. It is assumed that at each time period the firm can engage in a risky project which boosts current profits at the cost of liquidation in case of failure. The firm acts to maximize the present value of the expected cash flows. In this Section we specify the value of the firm in the absence of debt. Then, in Section 3, both the debt policy and the closure policy are considered and the value of the firm and the debt-holders' claims are specified.

At each time period, the firm may invest in a risky project inflating current operating profits by a given amount at the cost of bankruptcy if the project fails. In particular, we assume that there are $i=0,1,2, \ldots$ projects available, corresponding to different gambling strategies. At each time, if operative, a project $i$ yields, if successful, a profit $K \gamma_{i}$, while, with probability $p_{i}$ the project fails and the company goes bankrupt. We set $\gamma_{0}=0$ and $p_{0}=0$. Thus, project 0 may be interpreted as the "business as usual" case. Projects $i>0$ are risky, where we assume that $\gamma_{i+1}>\gamma_{i}$ and $p_{i+1}>p_{i}$, for each $i \geq 0$. Note that as $\gamma_{i}$ increases, that is the capability of boosting current profits by investing in the project increases, the probability of failure (and thus the riskiness of the project) has to increase in order to maintain the different gambling strategies relevant. We refer to $\gamma_{i}$ as a measure of the intensity of the gambling strategy.

In this section we consider only two projects 0 and 1 , that is, the company may either employ a gambling strategy (invest in project 1) or not (invest in project 0 ). In Section 4 we extend the 
framework to the case where the company may choose between different gambling intensities.

Let $V^{i}(x), i=0,1$, be the company's value in the case the firm invests in a risky project $(i=1)$ and in the case the firm does not $(i=0)$. The firm's value $V^{i}(x)$ satisfies the following equilibrium condition:

$$
r V^{i}=K x+\gamma_{i} K-f+\frac{1}{d t} E\left(d V^{i}\right)+p_{i}\left(H-V^{i}\right)
$$

for $i=0,1$. Applying Ito's Lemma we obtain

$$
r V^{i}=K x+\gamma_{i} K-f+\mu V_{x} x+\frac{1}{2} \sigma^{2} V_{x x} x^{2}+p_{i}\left(H-V^{i}\right)
$$

for $i=0,1$.

Note that the gain from the gamble, $K \gamma_{1}$, is constant and, by assumption, independent of the value $x$, while the loss in case of failure, $\left(V^{1}-H\right)$, depends on $x$. It will be shown that it is increasing in $x$. Thus, the lower (larger) is $x$, the larger (lower) is the relative gain from the risky investment. As a consequence, engaging in the gamble is optimal for sufficiently low values of $x$.

In what follows we shall use the notation:

$$
\widehat{x}_{i}=-\frac{\lambda_{i}}{1-\lambda_{i}} \frac{r H-\gamma_{i} K+f}{K} \frac{r+p_{i}-\mu}{r+p_{i}}
$$

for $i=0,1$, where $\lambda_{i}$ is the negative root of

$$
\mu \lambda_{i}+\frac{1}{2} \sigma^{2} \lambda_{i}\left(\lambda_{i}-1\right)=r+p_{i}
$$

for $i=0,1$.

In order to rule out the trivial cases throughout the paper we make the following assumption.

Assumption 1. $p_{1}$ and $\gamma_{1}$ are such that

$$
0<-\frac{\lambda_{1}}{1-\lambda_{1}}\left(H+\frac{f}{r}-\gamma_{1} \frac{K}{r}\right) \frac{r-\mu+p_{1}}{r+p_{1}}<-\frac{\lambda_{0}}{1-\lambda_{0}}\left(H+\frac{f}{r}\right) \frac{r-\mu}{r}
$$

Assumption 1 poses restrictions on the parameter values of $p_{1}$ and $\gamma_{1}$. In particular, for each value of $p_{1}$, Assumption 1 defines an upper and a lower bound for the parameter value $\gamma_{1}$ such 
that both the closure problem and the gambling option remain relevant, respectively. To see this, we observe that a too large value of $\gamma_{1}$ leads to a violation of the first inequality, posing an upper bound on the value of $\gamma_{1}$. A too large gambling intensity makes the optimal closure problem irrelevant. On the other hand, a too low value of $\gamma_{1}$ leads to an infringement of the second inequality ${ }^{2}$, setting a lower bound on the value of $\gamma_{1}$. A too low gambling intensity makes the option to engage in a last resort gambling strategy unattractive.

Proposition 1 characterizes the optimal firm value:

Proposition 1 The firm value is

$$
V(x)=\left\{\begin{array}{c}
V^{0}(x) \text { for } x \geq x_{0} \\
V^{1}(x) \text { for } \widehat{x}_{1} \leq x<x_{0} \\
H \quad \text { for } x<\widehat{x}_{1}
\end{array}\right.
$$

where

$$
\begin{gathered}
V^{0}(x)=\frac{K x}{r-\mu}-\frac{f}{r}+\left(\frac{f}{r}-\frac{K x_{0}}{r-\mu}+\frac{K x_{0}}{r+p_{1}-\mu}+\frac{p_{1} H+\gamma_{1} K-f}{r+p_{1}}\right)\left(\frac{x}{x_{0}}\right)^{\lambda_{0}}+ \\
\left(H-\frac{K \widehat{x}_{1}}{r+p_{1}-\mu}-\frac{p_{1} H+\gamma_{1} K-f}{r+p_{1}}\right)\left(\frac{x_{0}}{\widehat{x}_{1}}\right)^{\lambda_{1}-\lambda_{0}}\left(\frac{x}{\widehat{x}_{1}}\right)^{\lambda_{0}} \\
V^{1}(x)=\frac{K x}{r+p_{1}-\mu}+\frac{p_{1} H+\gamma_{1} K-f}{r+p_{1}}+ \\
\left(H-\frac{K \widehat{x}_{1}}{r+p_{1}-\mu}-\frac{p_{1} H+\gamma_{1} K-f}{r+p_{1}}\right)\left(\frac{x}{\widehat{x}_{1}}\right)^{\lambda_{1}}
\end{gathered}
$$

where $\widehat{x}_{1}$ is defined in (3) and $x_{0}$ is the solution of $F(x)=0$, where

$$
\begin{gathered}
F(x)=K x\left(1-\lambda_{0}\right)\left(\frac{1}{r-\mu}-\frac{1}{r-\mu+p_{1}}\right)+\frac{\lambda_{0}-\lambda_{1}}{1-\lambda_{1}}\left(\frac{r H-\gamma_{1} K+f}{r+p_{1}}\right)\left(\frac{x}{\widehat{x}_{1}}\right)^{\lambda_{1}}+ \\
\lambda_{0}\left(\frac{f}{r}+\frac{p_{1} H+\gamma_{1} K-f}{r+p_{1}}\right)
\end{gathered}
$$

and where Assumption 1 guarantees that $x_{0}>\widehat{x}_{1}$.

Proof. In the Appendix.

Proposition 1 identifies two thresholds, the first $\left(\widehat{x}_{1}\right)$ being the closure cut-off level and the second $\left(x_{0}\right)$ being a gamble cut-off level. If demand is sufficiently large (i.e. $x>x_{0}$ ), the company chooses not to engage in the risky investment. If demand decreases to intermediate values (i.e. for $\widehat{x}_{1}<x \leq x_{0}$ ), then gambling becomes optimal. The company boosts current profits, betting on a

\footnotetext{
${ }^{2}$ For $\gamma_{1}=0$ the second inequality is always violated since inequality $-\lambda_{0}<-\lambda_{1} \frac{1-\lambda_{0}}{1-\lambda_{1}} \frac{r}{r+p_{1}} \frac{r-\mu+p_{1}}{r-\mu}$ holds for each value of $p_{1}>0$.
} 
recovery of demand and thus trying to bridge good and bad times. If demand decreases further (i.e., $x \leq \widehat{x}_{1}$ ), closure becomes optimal (see Figure 1).

The firm's values as described in (5) - (6) have a straightforward interpretation. The first and the second term in (5) represent the present value of the firm's cash flow, the third expression in round brackets represents the option value of engaging in a last resort gamble, and the forth expression in round brackets represents the option value of shutting the firm down. The first and the second term in (6) represent the present value of the inflated cash flow. Note that in this case the values are discounted at a larger rate since the risky project fails with probability $p_{1}$, in which case the company goes bankrupt. The third expression in round brackets in (6) represents the option value of closure.

Observe that $V(x)$ is increasing in $x$ and therefore the loss if the risky project fails, is increasing in $x$ as well.

It is straightforward to show that $\widehat{x}_{1}$ is decreasing in $\gamma_{1}$ and increasing in $p_{1}$. Thus, the heavier the gamble, the more inflated the firm's value and the later closure occurs.

We compare the result with the case where a last resort gamble is not available. We denote by $V_{0}^{N G}(x)$ the firm's value satisfying (2) in the case where $\gamma_{0}=p_{0}=0$, then ${ }^{3}$

$$
V^{N G}(x)=\frac{K x}{r-\mu}-\frac{f}{r}+\left(H-\frac{K \widehat{x}_{0}}{r-\mu}+\frac{f}{r}\right)\left(\frac{x}{\widehat{x}_{0}}\right)^{\lambda_{0}}
$$

where $\widehat{x}_{0}$ is defined in (3).

Proposition 2 . If a last resort gamble is not available, then closure occurs at $\widehat{x}_{0}$, where $\widehat{x}_{0}>\widehat{x}_{1}$.

Proof. It follows from Assumption 1.

Thus, the firm closes later, if it can engage in a last resort gamble. The company invests in a risky project, inflating current profits and thus delaying the firm's liquidation (see Figure 1).

\footnotetext{
${ }^{3}$ See also Proposition 1 in Lambrecht and Myers (2005).
} 


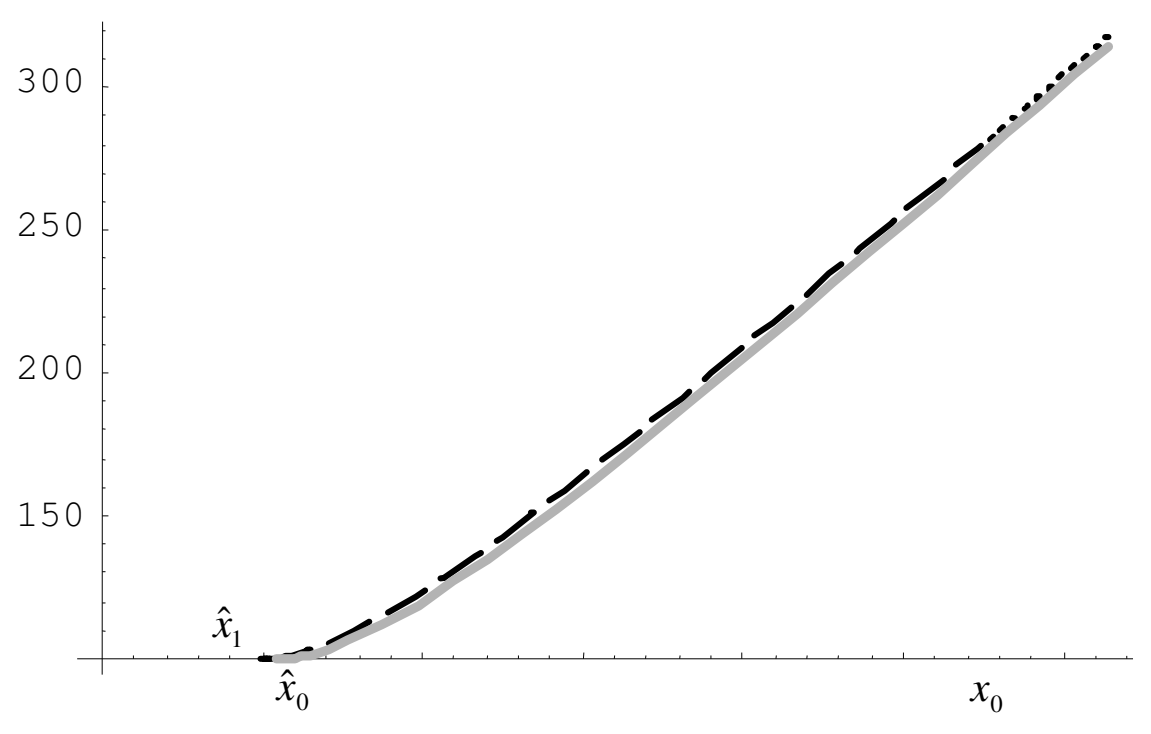

Figure 1: $V^{1}(x)$ (black dashed line), $V^{0}(x)$ (black dotted line) and $V^{N G}(x)$ (grey line) as a function of $x$. Parameter values: $\sigma=.25, r=.05, \mu=.001, p_{1}=.001, \gamma_{1}=.005, f=1$, $K=H=100$.

Note that a violation of the second inequality in Assumption 1 implies that $\widehat{x}_{1}>\widehat{x}_{0}$. In this case, it follows from Proposition 1 that investing in the risky project is never optimal. In other words, the company's value is larger if it does not engage in a last resort gamble even if it is available and, consequently, liquidation is optimal once exogenous demand decreases below the liquidation threshold $\widehat{x}_{0}$.

A final remark concerns the effect of volatility on closure.

Remark 1 An increase in the volatility parameter $\sigma^{2}$ decreases the closure thresholds $\widehat{x}_{1}$ and $\widehat{x}_{0}$.

The intuition is that as volatility increases, so does the value of the firm for a given closure threshold. With the terminology of real option theory, the premium to keep the closure option alive is weaker. This lowers the thresholds $\widehat{x}_{1}$ and $\widehat{x}_{0}$. Notice that the effect of $\sigma^{2}$ on $\widehat{x}_{1}$ has the same sign of the effect of $\gamma_{1}$. 


\section{Debt and Equity}

In this section we suppose that the firm is financed by issuing debt and equity and examine the effect of debt on the closure and gambling decisions. We assume that debt guarantees the payment of a constant perpetual coupon, $C$, unless the firm defaults on the coupon payment and declares bankruptcy, in which case liquidation occurs. The liquidation value, net of bankruptcy costs, is denoted by $H$. Two cases can be distinguished: (i) risk-free debt, where the company's liquidation value covers the value of the debt $\left(H \geq \frac{C}{r}\right)$, so that debt is fully collateralized, and (ii) risky debt, where the company's liquidation value is insufficient $\left(H<\frac{C}{r}\right)$. Let $E(x)$ denote the equity-holders' claim and $D(x)$ the debt-holders' claim.

In this section we use the following notation, which takes debt into account:

$$
x_{i}^{*}=-\frac{\lambda_{i}}{1-\lambda_{i}} \frac{r \Delta-\gamma_{i} K+C+f}{K} \frac{r+p_{i}-\mu}{r+p_{i}}
$$

where $\Delta=\max \left\{H-\frac{C}{r}, 0\right\}$ and $i \in\{0,1\}$. Observe that as long as debt is risk-free $x_{i}^{*}=\widehat{x}_{i}$, while if debt is risky then $x_{i}^{*}>\widehat{x}_{i}$.

Consider first the case of risk-free debt. We denote by $e(x)$ the payout policy to equityholders, being $e(x)=K x-f-C$ as long as the company remains operative and $r H-C$ in case of liquidation. We denote by $d(x)$ the payout policy to debt-holders, where $d(x)=C$. It is easy to see that

$$
\begin{gathered}
E(x)=V(x)-D(x) \\
D(x)=\frac{C}{r}
\end{gathered}
$$

where $V(x)$ is defined in Proposition 1. Thus, as long as debt is risk-free, the company's closure and gambling strategies are not affected by its capital structure.

Consider next the case of risky debt. Now, the payout policy to equity-holders is $e(x)=$ $K x-f-C$, as long as the company remains operative, and 0 in case of liquidation, while the 
payout policy to debt-holders is $d(x)=C$ as long as the company remains operative, and $r H$ in the case of liquidation. The following Proposition can be proved:

Proposition 3 (i) For coupon values lower than $\widehat{C}$, equity and debt values are

$$
\begin{gathered}
E(x)=\left\{\begin{array}{c}
E^{0}(x), \text { for } x>x_{0 R} \\
E^{1}(x), \text { for } x_{1}^{*}<x \leq x_{0 R} \\
0, \text { for } x \leq x_{1}^{*}
\end{array}\right. \\
D(x)=\left\{\begin{array}{c}
D^{0}(x), \text { for } x>x_{0 R} \\
D^{1}(x), \text { for } x_{1}^{*}<x \leq x_{0 R} \\
H, \text { for } x \leq x_{1}^{*}
\end{array}\right.
\end{gathered}
$$

where

$$
\begin{gathered}
E^{0}(x)=\frac{K x}{r-\mu}-\frac{f}{r}-\frac{C}{r}+\left(\frac{f}{r}+\frac{C}{r}-\frac{K x_{0 R}}{r-\mu}+\frac{K x_{0 R}}{r+p_{1}-\mu}-\frac{C-\gamma_{1} K+f}{r+p_{1}}\right)\left(\frac{x}{x_{0 R}}\right)^{\lambda_{0}}+ \\
\left(\frac{C-\gamma_{1} K+f}{r+p_{1}}-\frac{K x_{1}^{*}}{r+p_{1}-\mu}\right)\left(\frac{x_{0 R}}{x_{1}^{*}}\right)^{\lambda_{1}-\lambda_{0}}\left(\frac{x}{x_{1}^{*}}\right)^{\lambda_{0}} \\
E^{1}(x)=\frac{K x}{r+p_{1}-\mu}-\frac{C-\gamma_{1} K+f}{r+p_{1}}+ \\
\left(\frac{C-\gamma_{1} K+f}{r+p_{1}}-\frac{K x_{1}^{*}}{r+p_{1}-\mu}\right)\left(\frac{x}{x_{1}^{*}}\right)^{\lambda_{1}}
\end{gathered}
$$

where $x_{1}^{*}$ is defined in (8) and $x_{0 R}$ is the solution of $F^{R}(x)=0$, where

$$
\begin{gathered}
F^{R}(x)=K x\left(1-\lambda_{0}\right)\left(\frac{1}{r-\mu}-\frac{1}{r-\mu+p_{1}}\right)+\frac{\lambda_{0}-\lambda_{1}}{1-\lambda_{1}} \frac{C-\gamma_{1} K+f}{r+p_{1}}\left(\frac{x}{x_{1}^{*}}\right)^{\lambda_{1}}+ \\
\lambda_{0}\left(\frac{f}{r}+\frac{C}{r}-\frac{C-\gamma_{1} K+f}{r+p_{1}}\right)
\end{gathered}
$$

and where

$$
\begin{gathered}
D^{0}(x)=\frac{C}{r}\left[1-\left(\frac{x}{x_{0 R}}\right)^{\lambda_{0}}\right]+\frac{C+p_{1} H}{r+p_{1}}\left(\frac{x}{x_{0 R}}\right)^{\lambda_{0}}+\left(H-\frac{C+p_{1} H}{r+p_{1}}\right)\left(\frac{x_{0 R}}{x_{1}^{*}}\right)^{\lambda_{1}-\lambda_{0}}\left(\frac{x}{x_{1}^{*}}\right)^{\lambda_{0}} \\
D^{1}(x)=\frac{C+p_{1} H}{r+p_{1}}\left[1-\left(\frac{x}{x_{1}^{*}}\right)^{\lambda_{1}}\right]+H\left(\frac{x}{x_{1}^{*}}\right)^{\lambda_{1}}
\end{gathered}
$$

(ii) For coupon values $C \geq \widehat{C}$ engaging in a last resort gamble is never optimal and closure occurs for $x \leq x_{0}^{*}$, where $x_{0}^{*}$ is defined in (8).

Proof. In the Appendix.

The coupon value is critical for the company's decision to engage or not to engage in a last resort gamble. For sufficiently low coupon values, engaging in a last resort gamble is optimal in the case of a market downturn (i.e. for low values of $x$ ). Thus, the company inflates current profits betting on a market upturn. For sufficiently large coupon values engaging in a last resort gamble 
is never optimal. In this case, equity-holders are not able to gain from the gambling strategy which may benefit debt-holders, and thus it becomes an unattractive option.

The expressions of equity and debt values have a straightforward interpretation. The first two terms of $E^{1}(x)$ represent the present value of cash flow, given that the company engages in a last resort gamble; the other terms of $E^{1}(x)$ represent the closure option. Analogously, the first three terms of $E^{0}(x)$ represent the present value of profits, given that the firm does not invest in the risky project; the second expression in brackets represents the last resort gambling option value while the third part represents the closure option. The debt value can be interpreted in a similar way. Note that, while $\left(\frac{x}{x_{1}^{*}}\right)^{\lambda_{0}}$ can be interpreted as the probability that the manager shuts the company down because demand is too low ${ }^{4},\left(1-\left(\frac{x}{x_{1}^{*}}\right)^{\lambda_{0}}\right)$ can be interpreted as the probability that this event does not occur. Consider first $D^{1}(x)$ where the company employs the last resort gamble strategy. $\frac{C}{r+p_{1}}$ represents the present value of the constant perpetual coupon $C$, given that the company is not liquidated, where the discount factor takes into account the default probability $p_{1}$ of the risky project; $\frac{p_{1} H}{r+p_{1}}$ represents the present value of the liquidation value if the risky project fails, given that the company is not liquidated. Thus, the first part of $D^{1}(x)$ represents the debt value if the company is not liquidated, while the second part consists of the expected debt value in the case of liquidation. The debt value $D^{0}(x)$, corresponding to the case where the company does not employ the last resort gamble strategy, consists of three parts. The first represents the present value of debt, given that the company does not engage in a last resort gamble, the second expression represents the debt value due to the company's gambling option and the final term represents the debt value due the company's liquidation option. Note that in the case of risky debt $\left(\frac{C}{r}>H\right)$ the third expression is always negative.

A further remark concerns the optimality of the liquidation threshold $x_{1}^{*}$ from a "social" point of view. Notice that $\frac{\partial E^{1}(x)}{\partial x_{1}^{*}}=0$ and $\frac{\partial^{2} E^{1}(x)}{\partial\left(x_{1}^{*}\right)^{2}}<0$, that is, the choice of the closure threshold $x_{1}^{*}$ is optimal for equity-holders. On the contrary, $\frac{\partial V(x)}{\partial x_{1}^{*}}<0$, where $V(x)$ is the overall value of the

\footnotetext{
${ }^{4}$ This probability is different from the case where bankruptcy is induced by the failure of the risky project.
} 


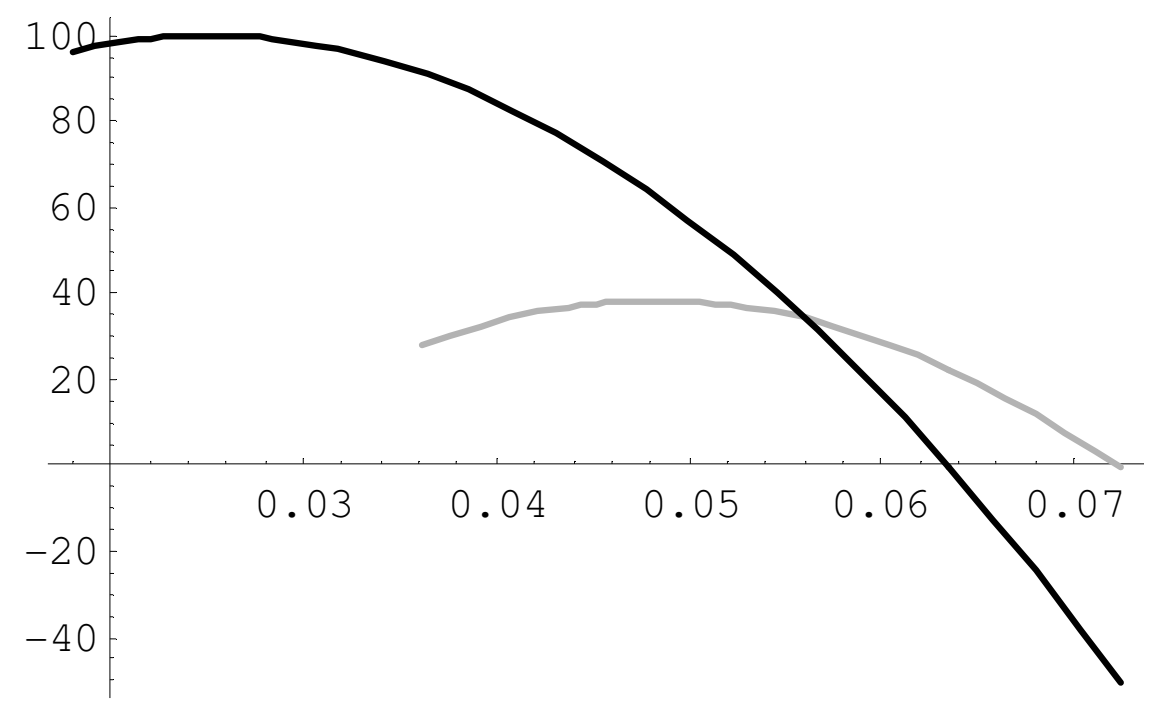

Figure 2: Equity value $E(x)$ (gray line) and the firm's value $V(x)$ (black line) as a function of the liquidation threshold $x_{1}^{*}$. Parameter values: $\sigma=.25, r=.05, \mu=.001, p_{1}=.001, \gamma_{1}=.005$, $f=1, K=H=100, C=10$.

firm, that is, $V(x)=E(x)+D(x)$. Since in this framework the socially optimal bankruptcy trigger is the one that maximizes the overall value of the firm $V(x)$, we get that, when equityholders choose the timing of bankruptcy and the firm has issued debt, then the socially optimal bankruptcy strategy cannot be achieved, that is, $x_{1}^{*}$ is not socially optimal. The cause is equityholders' limited liability. In particular, since by the envelope theorem $\frac{\partial V\left(x_{1}^{*}\right)}{\partial x_{1}^{*}}=\frac{\partial D\left(x_{1}^{*}\right)}{\partial x_{1}^{*}}<0$ the "socially optimal" liquidation threshold is lower than $x_{1}^{*}$. (See Figure 2 for an example.)

The following Remark can be proved straightforwardly.

Remark 2. Since under risky debt $C>r H$, liquidation occurs earlier than with risk-free debt, or an unleveraged firm, i.e. $x_{1}^{*}>\widehat{x}_{1}$.

Observe that the closure threshold $x_{1}^{*}$ is increasing in the coupon value $C$. Thus, debt speeds up closure: the leveraged firm closes earlier than the unleveraged one. Remark 2 is in keeping with what is established in the "debt overhang problem" literature (Myers, 1977). 
Proposition 4 Increasing the coupon value $C$ reduces the range of values where employing a last resort gamble strategy is optimal (i.e. $x_{1}^{*}-x_{0 R}$ is decreasing in $C$ ) and the distortion in liquidation induced by last resort gambles (i.e. $x_{0}^{*}-x_{1}^{*}$ is decreasing in $C$ ).

Proof. In the Appendix.

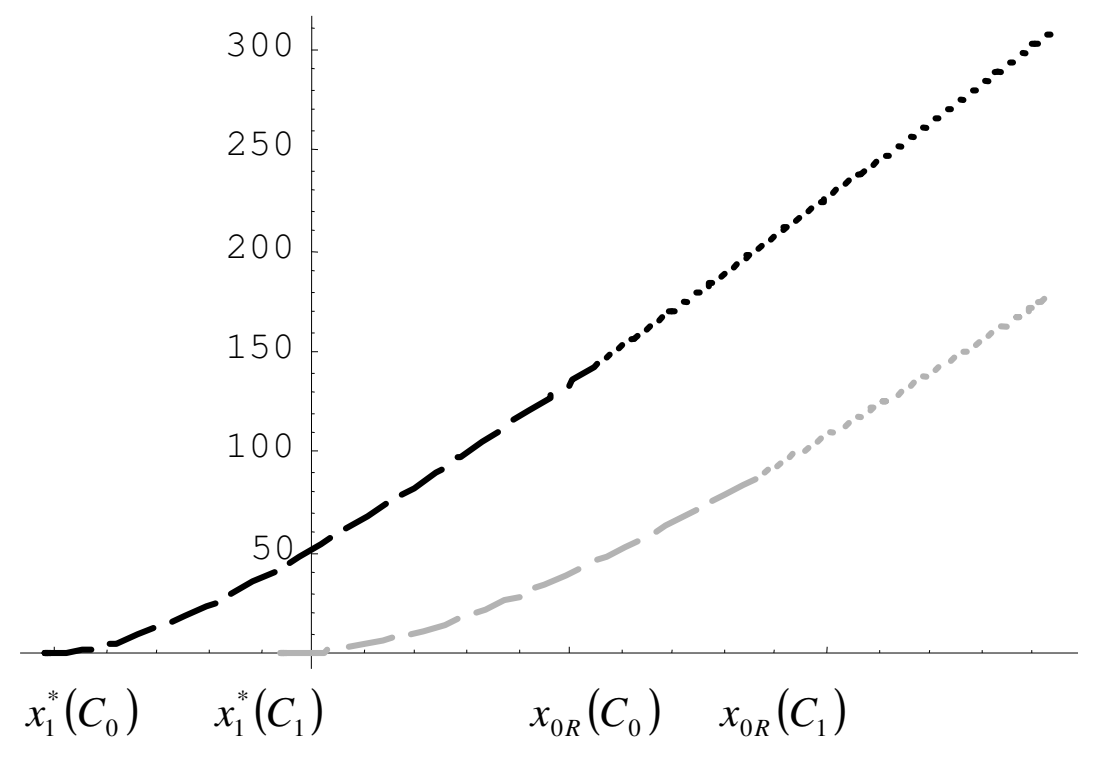

Figure 3: Equity values $E^{1}(x)$, dashed line, and $E^{0}(x)$, dotted line, for coupon values $C_{0}$ (black line) and $C_{1}$ (gray line) with $C_{1}>C_{0}$. Parameter values: $\sigma=.25, r=.05, \mu=.001, p_{1}=.001$, $\gamma_{1}=.005, f=1, K=H=100, C_{0}=10, C_{1}=20$.

Increasing $C$ reduces the equity-holders' gains from a last resort gamble. In Figure 3 we depict an example with two different coupon values $C_{1}>C_{0}$. For coupon value $C_{0}\left(C_{1}\right)$, investing in a risky project is optimal for values of $x \in\left(x_{1}\left(C_{0}\right), x_{0 R}\left(C_{0}\right)\right)\left(x \in\left(x_{1}\left(C_{1}\right), x_{0 R}\left(C_{1}\right)\right)\right)$, while for values of $x \geq x_{0 R}\left(C_{0}\right)\left(x \geq x_{0 R}\left(C_{1}\right)\right)$ it is not. Note that $x_{0 R}\left(C_{0}\right)-x_{1}^{*}\left(C_{0}\right)>x_{0 R}\left(C_{1}\right)-x_{1}^{*}\left(C_{1}\right)$ and thus a larger coupon value reduces the range of values for $x$ where engaging in a last resort gamble is optimal. Closure is optimal for values of $x \leq x_{1}^{*}\left(C_{0}\right)\left(x \leq x_{1}^{*}\left(C_{1}\right)\right)$. Thus, an increase in the coupon value speeds up liquidation $\left(x_{1}^{*}\left(C_{0}\right)<x_{1}^{*}\left(C_{1}\right)\right)$.

In Figure 4 we depict the liquidation (black line) and the gambling (gray line) threshold as a function of the coupon value $C$. For each $C<\widehat{C}$ the gambling threshold is larger than the 


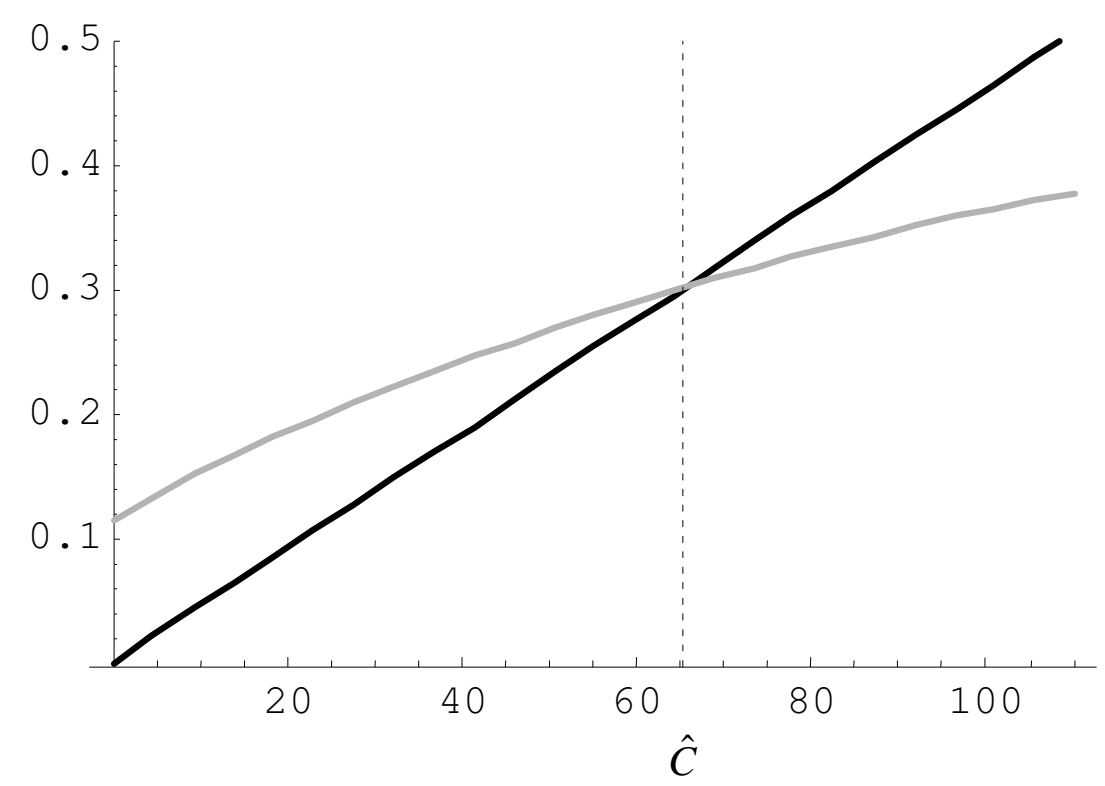

Figure 4: Liquidation (black line) and fraud (gray line) thresholds as a function of the coupon value $C$. Parameter values: $\sigma=.25, r=.05, \mu=.001, p_{1}=.001, \gamma_{1}=.005, f=1, K=H=100$.

liquidation threshold (i.e. $x_{1}^{*}<x_{0 R}$ ) and thus the last resort gamble strategy is optimal for values of $x$ between these two thresholds. As $C$ increase both the gamble and the liquidation threshold increase while the difference between the two decreases, reducing the values of $x$ where last resort gambling is optimal. For the coupon value $C \geq \widehat{C}$ investing in the risky project is never optimal.

Remark 3. An increase in the volatility parameter $\sigma^{2}$ decreases the closure thresholds $x_{1}^{*}$ and $x_{0}^{*}$. An increase in $\gamma_{1}$ decreases $x_{1}^{*}$.

As asset risk rises, so does the value of equity for a given closure threshold. Hence, equityholders' incentive to default on the interest payment, i.e. on the premium to keep the option alive is weaker. Notice that $\frac{\partial E(x)}{\partial \sigma^{2}}>0$, as long as bankruptcy has not been declared, that is, equity value is enhanced by greater risk in case of debt. This lowers the triggers $x_{1}^{*}$ and $x_{0}^{*}$. Notice that the effect of $\sigma^{2}$ on $x_{1}^{*}$ has the same sign of the effect of $\gamma_{1}$.

We investigate how a last resort gamble strategy affects the debt value. An issue concerns the 


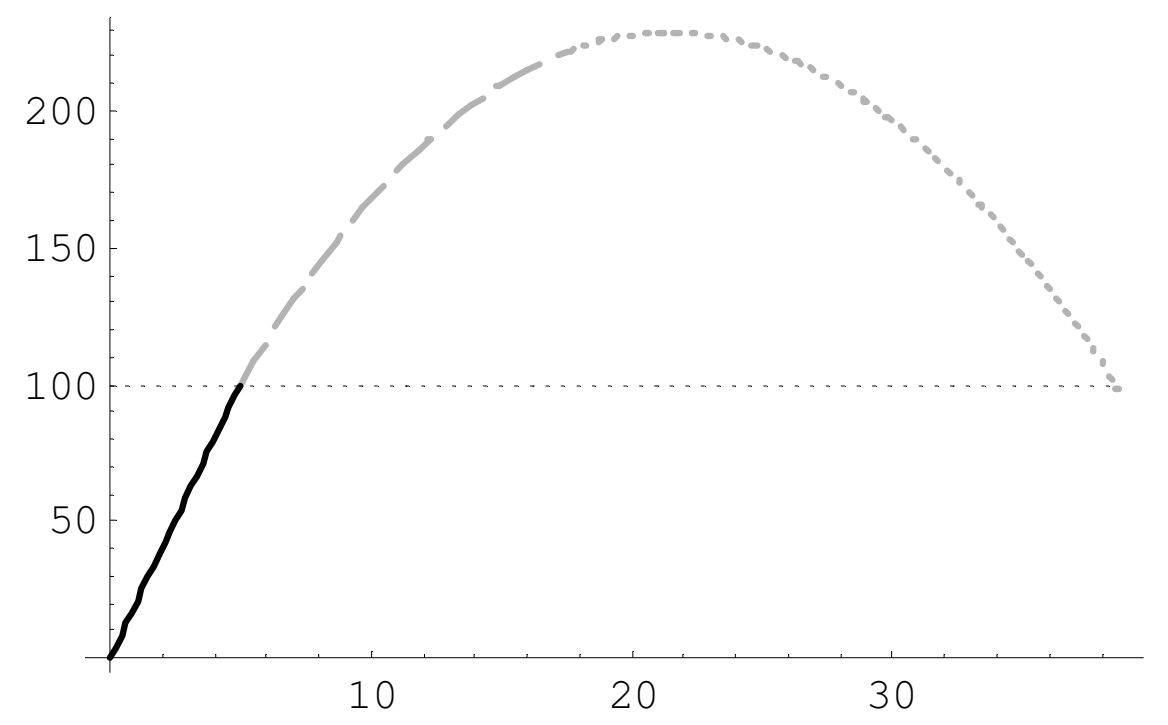

Figure 5: Debt capacity. In the Figure we depict the debt value as a function of $C$, holding the value of $x$ fixed. For small values of $C$ the debt is risk free (black continuous line). Increasing the value of $C$ the debt becomes risky but the company does not engage in a last resort gamble (gray dashed line); increasing further $C$ engaging in the last resort gamble becomes optimal (gray dotted line). Parameter values: $\sigma=.25, r=.05, \mu=.001, p_{1}=.001, \gamma_{1}=.005, f=1, K=H=100$.

debt capacity of the firm. For a given value of $x$, we study how the debt value $D(x)$ changes as a function of the coupon value $C$. For $C \leq r H$ the debt is risk-free and thus for $C=r H$ the debt value is $H$. For $C>r H$ the debt is risky and for a sufficiently large coupon value $C^{\prime \prime}$ the company defaults on its debt. Thus, since the debt value is a continuous function of $C$, there exists a $C \in\left(r H, C^{\prime \prime}\right)$ where the debt value is maximized. In Figure 5 we just depict an example based on the numerical example of Figure 4, where we fix $x=0.18$.

We now compare the debt value in the case of last resort gamble strategies to the case where these are not available. If last resort gambles are not available then the debt value is

$$
D^{N G}(x)=\left\{\begin{array}{c}
\frac{C}{r}\left[1-\left(\frac{x}{x_{0}^{*}}\right)^{\lambda_{0}}\right]+H\left(\frac{x}{x_{0}^{*}}\right)^{\lambda_{0}}, \text { for } x>x_{0}^{*} \\
H, \text { for } x \leq x_{0}^{*}
\end{array}\right.
$$

That is, the value of risky debt equals the value of the risk-free debt $\frac{C}{r}$ times the probability that bankruptcy does not occur plus the value of the proceeds from asset liquidation in the event of bankruptcy $H$ times the probability of bankruptcy. To see how risky investments affect the debt 
value we compute $\Delta D(x) \equiv D(x)-D^{N G}(x)$, where $D(x)$ is defined in Proposition 3

$$
\Delta D(x)=\left(\frac{C}{r}-H\right)\left\{\begin{array}{c}
\left(\frac{x}{x_{0 R}}\right)^{\lambda_{0}}\left[\left(\frac{x_{0 R}}{x_{0}^{*}}\right)^{\lambda_{0}}-\frac{p_{1}}{r+p_{1}}-\frac{r}{r+p_{1}}\left(\frac{x_{0 R}}{x_{1}^{*}}\right)^{\lambda_{1}}\right], \text { for } x>x_{0 R} \\
{\left[\left(\frac{x}{x_{0}^{*}}\right)^{\lambda_{0}}-\frac{p_{1}}{r+p_{1}}-\frac{r}{r+p_{1}}\left(\frac{x}{x_{1}^{*}}\right)^{\lambda_{1}}\right], \text { for } x_{0}^{*}<x \leq x_{0 R}} \\
\frac{r}{r+p_{1}}\left[1-\left(\frac{x}{x_{1}^{*}}\right)^{\lambda_{1}}\right], \text { for } x_{1}^{*}<x \leq x_{0}^{*} \\
0, \text { for } x \leq x_{1}^{*}
\end{array}\right.
$$

Note that, for $x_{1}^{*}<x \leq x_{0}^{*}, \Delta D(x)$ is always positive. For other values of $x$ it may happen that $\Delta D(x)$ is negative. For a sufficiently large difference $x_{0 R}-x_{0}^{*}$, we get $\left(\frac{x_{0 R}}{x_{0}^{*}}\right)^{\lambda_{0}}<\frac{p_{1}}{r+p_{1}}+$ $\frac{r}{r+p_{1}}\left(\frac{x_{0 R}}{x_{1}^{*}}\right)^{\lambda_{1}}$, so that $\Delta D(x)<0$ for $x>x_{0 R}$ and also for some values of $x_{0}^{*}<x \leq x_{0 R}$. The coupon value has an important role on the difference $\Delta D(x)$. A larger coupon value, reducing the incentives to engage in a last resort gamble and reducing the distortion induced by this strategy (see Proposition 4), increases the probability that $\Delta D(x)$ is positive. In Figure 6 we plot a numerical example. Consider, for example, the case of $x$ taking the value 0.5. For a low coupon value $(C=10)$ the debt value in case where a last resort gamble is available is lower than if none is available $(\Delta D(.5)$ is negative); increasing the coupon value to, for example, $C=30$ or to $C=60$ makes the differences between the two debt values $(\Delta D(.5))$ become positive.

\section{Gambling intensity}

In this Section we generalize the results obtained in Section 3 introducing different gambling intensities. While in the previous section the choice was either to invest in a risky project or not, here we introduce the choice among different risky projects with different gambling intensities. As an example we restrict our analysis to the case of two risky projects. The available projects are $i=0,1,2$ where $\gamma_{2}>\gamma_{1}>\gamma_{0}=0$ and $p_{2}>p_{1}>p_{0}=0$. The model can be extended straightforwardly to the case of $n$ degrees of gambling intensities.

For the remaining part of the paper we make use of Assumption 2 which generalizes Assumption 1. 


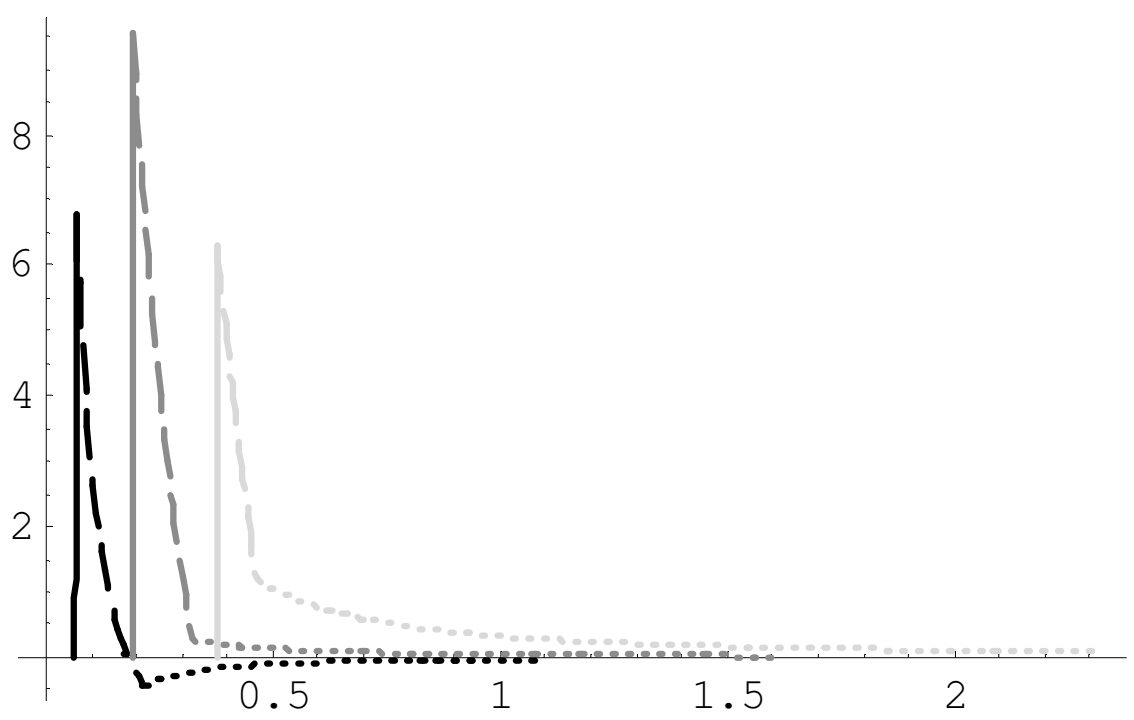

Figure 6: $\Delta D(x)$ as a function of $x ; x_{1}^{*}<x \leq x_{0}^{*}$ continuous line, $x_{0}^{*}<x \leq x_{0 R}$ dashed line and $x>x_{0 R}$ dotted line; increased brightness corresponds to an increased coupon value $C$. Parameter values: $\sigma=.15, r=.05, \mu=.001, p_{1}=.001, \gamma_{1}=.005, f=1, K=H=100 ., C=10$ (black line), $C=30$ (gray line), $C=60$ (light gray line).

Assumption $2 p_{i}$ and $\gamma_{i}$, for $i=0,1,2$ are such that

$$
0<-\frac{\lambda_{i+1}}{1-\lambda_{i+1}}\left(H+\frac{f}{r}-\gamma_{i+1} \frac{K}{r}\right) \frac{r-\mu+p_{i+1}}{r+p_{i+1}}<-\frac{\lambda_{i}}{1-\lambda_{i}}\left(H+\frac{f}{r}-\gamma_{i} \frac{K}{r}\right) \frac{r-\mu+p_{i}}{r+p_{i}}
$$

for each $i=0,1$ and $\gamma_{1}$ is sufficiently large.

For given values of $p_{1}$ and $p_{2}$, Assumption 2 poses restrictions on gambling intensities $\gamma_{1}$ and $\gamma_{2}$. To maintain the closure problem relevant, the capability to inflate current profits must be limited, posing an upper bound on $\gamma_{2}$ (first part of the inequality in Assumption 2 for $i=1$ ). To maintain the gambling problem relevant at different gambling levels, the second part of the inequality in Assumption 2, for $i=0,1$, establishes a relationship between $\gamma_{1}$ and $\gamma_{2}$, defining a lower bound on $\gamma_{2}$ as well as an upper and a lower bound on $\gamma_{1}$.

Assumption 3 is required in order to have the choice of different gambling levels meaningful for the relevant parameter configurations. 
Assumption $3 p_{i}$ and $\gamma_{i}, i=0,1,2$ are such that

$$
-\frac{\lambda_{2}}{1-\lambda_{2}} \frac{r-\mu+p_{2}}{r+p_{2}}+\frac{\lambda_{1}}{1-\lambda_{1}} \frac{r-\mu+p_{1}}{r+p_{1}}>-\frac{\lambda_{1}}{1-\lambda_{1}} \frac{r-\mu+p_{1}}{r+p_{1}}+\frac{\lambda_{0}}{1-\lambda_{0}} \frac{r-\mu}{r}
$$

The following Proposition characterizes the equity-holders and debt-holders claims in the case of risky debt and shows that a gradual increase in gambling intensity is optimal as demand decreases for low values of the coupon, while for large values of the coupon high gambling intensity is never optimal.

Proposition 5 There exists a coupon value $\bar{C}$ such that for $C \leq \bar{C}$ the equity and debt values are

$$
\begin{gathered}
E(x)=\left\{\begin{array}{c}
E^{0}(x) \text { for } x_{0 L}<x \\
E^{1}(x) \text { for } x_{1 L}<x \leq x_{0 L} \\
E^{2}(x) \text { for } x_{2}^{*}<x \leq x_{1 L} \\
0 \text { for } x \leq x_{2}^{*}
\end{array}\right. \\
D(x)=\left\{\begin{array}{c}
D^{0}(x) \text { for } x_{0 L}<x \\
D^{1}(x) \text { for } x_{1 L}<x \leq x_{0 L} \\
D^{2}(x) \text { for } x_{2}^{*}<x \leq x_{1 L} \\
0 \text { for } x \leq x_{2}^{*}
\end{array}\right.
\end{gathered}
$$

where the closure threshold $x_{2}^{*}$ is defined in (8), for $i=2, x_{1 L}$ is the solution of $F^{1}(x)=0$, and $x_{0 L}$ is the solution of $F^{0}(x)=0$, where $F^{1}(x), F^{0}(x)$ and $E^{i}(x)$, for $i=0,1,2$, are defined in the Appendix, and where Assumptions 2 and 3 guarantee that $x_{0 L}>x_{1 L}>x_{2}^{*}$. For $C>\bar{C}$ Proposition 3 applies, where Assumption 3 guarantees that $\bar{C}<\widehat{C}$.

Proof. In the Appendix.

For coupon values lower than $\bar{C}$ the company increases the gambling intensity as $x$ decreases. For large values of $x$ the company does not engage in a last resort gamble strategy $\left(x>x_{0 L}\right)$. As $x$ decreases, the company starts to invest in the risky project 1 which corresponds to a low gambling intensity $\gamma_{1}$ (for $x \in\left(x_{1 L}, x_{0 L}\right)$ ). As $x$ decreases further, the company increases its gambling intensity, investing in the risky project 2 (for $x \in\left(x_{2}^{*}, x_{1 L}\right)$ ), delaying further liquidation. For coupon values larger than $\bar{C}$ investing in the risky project 2 is never optimal, while it remains optimal to invest in the risky project 1 for some values of $x$. Thus, as $C$ increases the intensity of the last resort gambles decreases. 


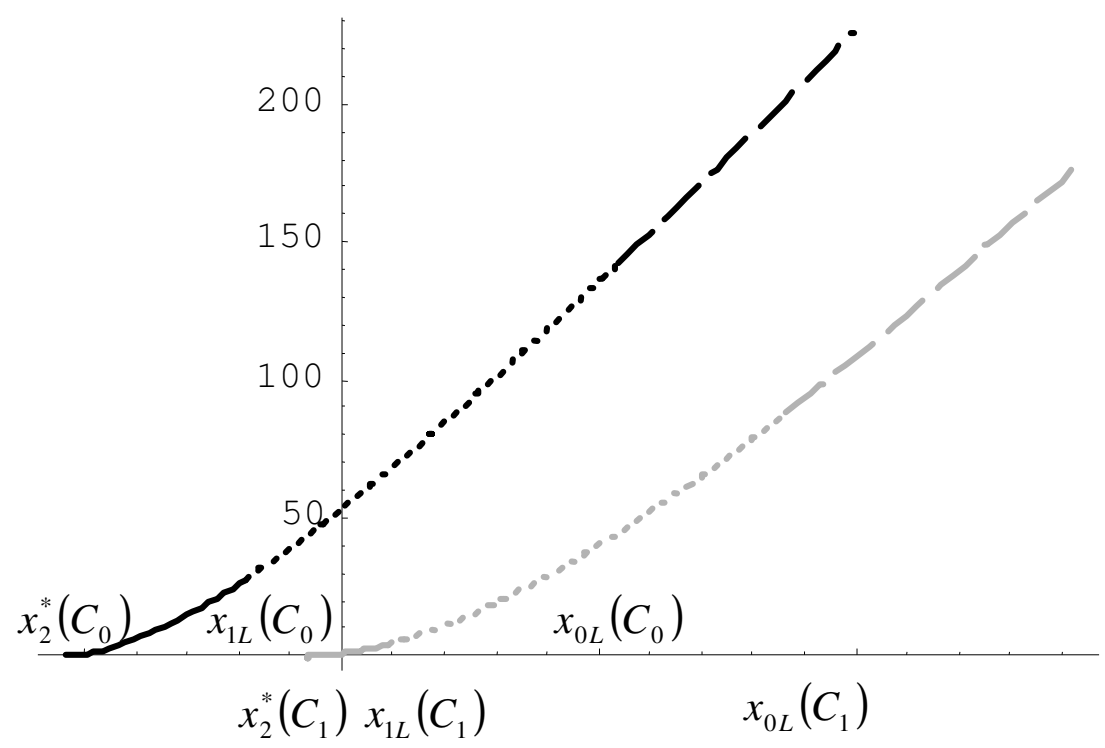

Figure 7: Equity values $E^{2}(x)$, continuous line, $E^{1}(x)$, dotted line, and $E^{0}(x)$, dashed line, for coupon values $C_{0}$ (black line) and $C_{1}$ (grey line) with $C_{1}>C_{0}$. Parameter values: $\sigma=.25$, $r=.05, \mu=.001, p_{1}=.001, p_{2}=.005, \gamma_{1}=.005, \gamma_{2}=.0125, f=1, K=H=100, C_{0}=10$, $C_{1}=20$.

Remark 4 For values of $C>r H$, increasing the coupon value $C$ reduces the last resort gambling intensity.

Note that while in the previous section the gambling intensity was given, in this section here the firm chooses between different gambling intensities. A change in the firm's financial structure leads the firm to choose a different last resort gambling intensities. A higher coupon value leads a firms to engage a less intense gambling strategy. In Figure 7 we depict a typical situation with two different coupon values $C_{1}>C_{0}$. Observe that a larger coupon value reduces the range of values of $x$ where investing in project 1 is optimal $\left(x_{0 L}\left(C_{1}\right)-x_{1 L}\left(C_{1}\right)>x_{0 L}\left(C_{0}\right)-x_{1 L}\left(C_{0}\right)\right)$ and where investing in project 2 is optimal $\left(x_{1 L}\left(C_{1}\right)-x_{2}^{*}\left(C_{1}\right)>x_{1 L}\left(C_{0}\right)-x_{2}^{*}\left(C_{0}\right)\right)$. Moreover, observe that the reduction in the latter range is larger than the reduction in the former one. For a sufficiently large coupon value, investing in project 2 will never be optimal, while investing in project 1 remains optimal for some values of $x$. 


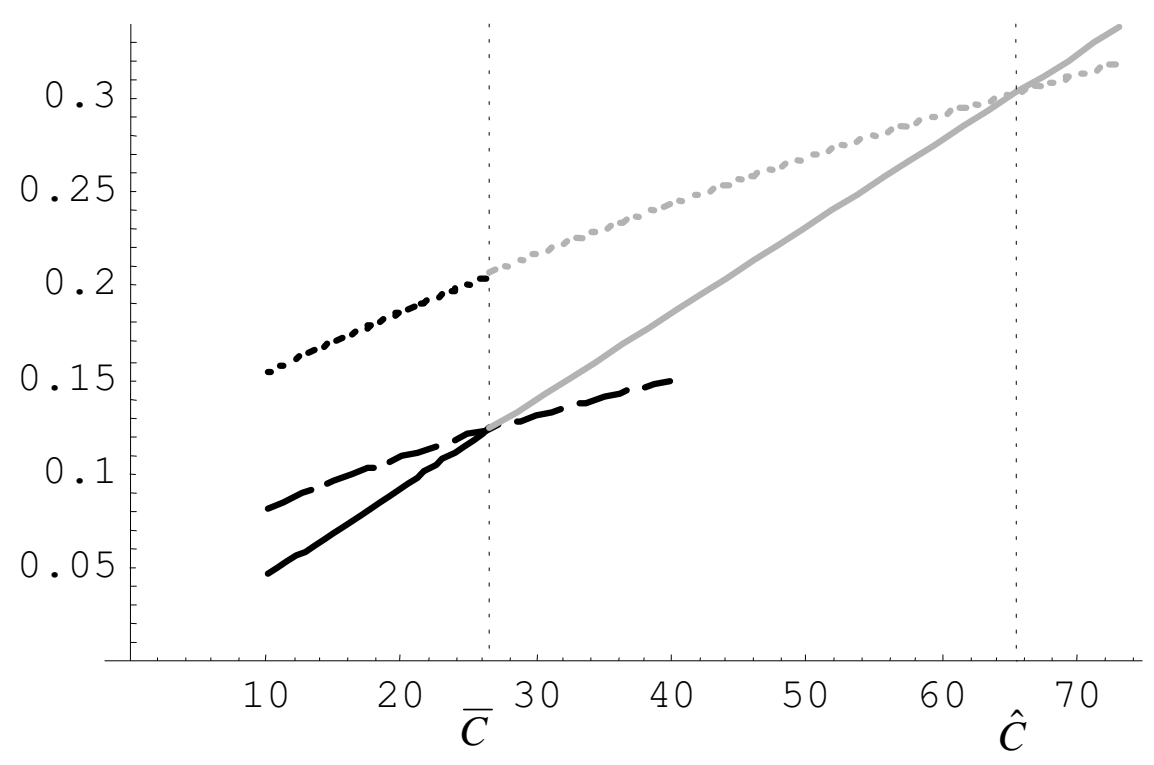

Figure 8: For $C<\bar{C}$ we depict the gambling threshold for project 1 (black dotted line), for project 2 (black dashed line) and the liquidation threshold (black continuous line) as a function of $C$. For $\bar{C} \leq C<\widehat{C}$ we depict the gambling threshold for project 1 (gray dotted line) and the liquidation threshold (gray continuous line) as a function of $C$. Parameter values: $\sigma=.25, r=.05, \mu=.001$, $p_{1}=.001, p_{2}=.005, \gamma_{1}=.005, \gamma_{2}=.0125, f=1, K=H=100$.

In Figure 8 we depict an example of gamble and liquidation thresholds as a function of $C$.

\section{Conclusion}

The problem of the relation between last resort gambles, debt and liquidation policies is set out in this paper within a real option model.

Of course, a few extensions and generalizations of the model can be explored. In the present model, for given coupon value, we make some comparative statics analyses to show how optimal last resort gambling and liquidation policies are affected by the company's indebtedness. One can determine the optimal coupon value and study an endogenous capital structure.

The model also abstracts from conflicts of interests between managers and shareholders. By introducing asymmetric information it would be interesting to study the fraudulent aspect of last resort gambles. Interests between managers and equity-holders in generally are not aligned 
because, for example, managers and equity-holders face different time horizons. Within such a model one could explore how endogenous capital structure may act as an incentive device, and under which circumstances the optimal debt policy can be used to affect last resort gamble strategies. In this context, alternative management compensation schemes may have a role as well.

\section{References}

Akerlof, G.A. and P.M. Romer (1993). Looting: The Economic Underworld of Bankruptcy for Profit, Brookings Papers on Economic Activity, 1993, 1-73.

Bebchuk, L and J. Fried (2003). Executive Compensation as an Agency Problem, Journal of Economic Perspectives, 71-92.

Bebchuk, L and J. Fried (2004). Pay without Performance: the Unfulfilled Promise of Executive Compensation, Harvard University Press.

Bergstresser, D. and T. Philippon (2006). CEO incentives and earnings management, Journal of Financial Economics, 80, 511-529.

Bolton, P. Scheinkman, J. and W. Xiong (2006). Executive Compensation and Short-termist Behaviour in Speculative Martkets. Review of Economic Studies, 73, 577-610.

Bolton, P. Scheinkman, J. and W. Xiong (2005). Pay for Short-term Performance: Executive Compensation in Speculative Markets. Forthcoming Journal of Corporation Law.

Burns, N., and S. Kedia (2006). The Impact of Performance-Based Compensation on Misreporting. Journal of Financial Economics, 79, 35-67.

Decamps, J.-P. and A. Faure-Grimaud (2002). Excessive continuation and dynamic agency costs of debt, European Economic Review, 46, 1623-1644.

Erickson, M, Hanlon, M. and E. Maydew (2006). Is there a Link between Executive Compensation and Accounting Fraud? Journal of Accounting Research, 44, 113-143.

Friebel and Guriev (2005). Earnings Manipulation and Incentives in Firms, CEPR W.P. 4850

Goldman, E. and S.L. Slezak (2006). An equilibrium model of incentive contracts in the presence of information manipulation, Journal of Financial Economics, 80, 603-626.

Hart, O. (2000). Different Approaches to Bankruptcy. NBER Working Paper No. 7921.

Jensen, M.C. (2004). The Agency Costs of Overvalued Equity and the Current State of Corporate Finance. European Financial Management, 10, 549-565.

Johnson, S.A., Ryan, H.E. and Y.S. Tian (2006). Managerial Incentives and Corporate Fraud: The Sources of Incentives Matter, mimeo.

Knot, O. and O. Vychodil (2006). Bankruptcy Regimes and Gambling on Resurrection, CERGE-EI W.P.. 
Lambrecht, B.M. and S.C. Myers (2005), Debt and Agency in a Real-Options Model of the Firm, mimeo.

Leland, H.E. (1998). Agency Costs, Risk Management, and Capital Structure, Journal of Finance, 53, 1213-1243

Moeller, Schlingemann and Stulz (2003). Wealth Destruction on a Massive Scale? A Study of Acquiring-Firm returns in the recent Merger Wave, available from http://papers.ssrn.com/Abstract $=476421$.

Myers, S.C. (1977). Determinants of Corporate Borrowing, Journal of Financial Economics, $5,147-176$.

Narayanan, M.P.(1985). Managerial Incentives for Short-Term Results, Journal of Finance, 40, 1469-1484.

Povel, P., R. Singh and A. Winton (2006). Booms, Busts, and Fraud. Forthcoming Review of Financial Studies.

Stein, J.C. (1989). Efficient Capital Markets, Inefficient Firms: A Model of Myopic Corporate Behavior, Quarterly Journal of Economics, 104, 655-669.

Von Thadden E.-L. (1995). Long-Term Contracts, Short-Term Investment and Monitoring, Review of Economics Studies, 62, 557-575.

\section{Appendix}

Proof of Proposition 1. The solution to the differential equation (2) is

$$
V^{0}(x)=\frac{K x}{r-\mu}-\frac{f}{r}+A_{1} x^{\lambda_{0}}+A_{2} x^{\beta}
$$

where $\lambda_{0}$ and $\beta$ are the negative and positive roots of (4), respectively. A no bubble condition requires $\lim _{x \rightarrow \infty}\left(V^{0}(x)-\frac{K x}{r-\mu}+\frac{f}{r}\right)=0$ and thus $A_{2}=0$. The solution to the differential equation (2) is

$$
V^{1}(x)=\frac{K x}{r+p_{1}-\mu}+\frac{p_{1} H+\gamma_{1} K-f}{p_{1}+r}+B_{1} x^{\lambda_{1}}+B_{2} x^{\varepsilon}
$$

where $\lambda_{1}$ and $\varepsilon$ are the negative and positive roots of (4), respectively. Since for large values of $x$ the option value of closure becomes negligible, $B_{2}=0$. The value matching condition $V^{1}\left(\widehat{x}_{1}\right)=H$ together with the smooth pasting condition $V_{x}^{1}\left(\widehat{x}_{1}\right)=0$ define the closure threshold $\widehat{x}_{1}$ and $B_{1}$, while the value matching condition $V^{1}\left(x_{0}\right)=V^{0}\left(x_{0}\right)$ together with the smooth pasting condition $V_{x}^{1}\left(x_{0}\right)=V_{x}^{0}\left(x_{0}\right)$ define the gamble threshold $x_{0}$ and the constant $A_{1}$. 
Substituting $\widehat{x}_{i}$ for $i=0,1$, as defined in (3), into $F(x)$ we obtain

$$
\begin{gathered}
F(x)=\left(1-\lambda_{0}\right) \frac{K}{r-\mu}\left(x-\widehat{x}_{0}\right)-\left(1-\lambda_{0}\right) \frac{K}{r+p_{1}-\mu}\left(x-\widehat{x}_{1}\right)+ \\
-\frac{\lambda_{0}-\lambda_{1}}{\lambda_{1}} \frac{K \widehat{x}_{1}}{r+p_{1}-\mu}\left[\left(\frac{x}{\widehat{x}_{1}}\right)^{\lambda_{1}}-1\right]
\end{gathered}
$$

Assumption 1 guarantees that $F\left(\widehat{x}_{1}\right)<0$ and since $F(x)$ is a convex function where $\lim _{x \rightarrow \infty} F(x)=$ $\infty$, a unique solution to $F\left(x_{0}\right)=0$ exists and moreover $x_{0}>\widehat{x}_{1}$. Moreover, $F\left(\widehat{x}_{0}\right)<0$ and thus, following the same argument, we obtain $x_{0}>\widehat{x}_{0}>\widehat{x}_{1}$.

Proof of Proposition 3. We divide the proof into two parts. In part (a) we show the content of Proposition 3 (i). In part (b) we show that $\widehat{C}$ exists.

Part (a). To compute $D^{i}(x)$, let us solve the following differential equation:

$$
r D^{i}=C+\mu D_{x}^{i} x+\frac{1}{2} \sigma^{2} D_{x x}^{i} x^{2}+p_{i}\left(H-D^{i}\right)
$$

for $i=0$ for $x>x_{0 R}$ and $i=1$ for $x_{1}^{*}<x \leq x_{0 R}$. The general solution of (9) is $\frac{C+p_{i} H}{r+p_{i}}+L_{i} x^{\lambda_{i}}$ for some $L_{i}$, if we take the no-bubble condition into account. We determine $L_{1}$ employing the boundary condition $D^{1}\left(x_{1}^{*}\right)=H$ and $L_{0}$ employing the value matching condition $D^{0}\left(x_{0 R}\right)=$ $D^{1}\left(x_{0 R}\right)$.

The value of the equity-holders' claim $E(x)$ is obtained solving the differential equations:

$$
\begin{gathered}
r E^{0}=K x-f-C+\mu E_{x}^{0} x+\frac{1}{2} \sigma^{2} E_{x x}^{0} x^{2}, \text { for } x>x_{0 R} \\
r E^{1}=K x+\gamma_{1} K-f-C+\mu E_{x}^{1} x+\frac{1}{2} \sigma^{2} E_{x x}^{1} x^{2}+p_{1}\left(-E^{1}\right), \text { for } x_{1}^{*}<x \leq x_{0 R}
\end{gathered}
$$

whose solutions are $E^{0}(x)=\frac{K x}{r-\mu}-\frac{f}{r}-\frac{C}{r}+A x^{\lambda_{0}}$ and $E^{1}(x)=\frac{K x}{r+p_{1}-\mu}-\frac{C-\gamma_{1} K+f}{p_{1}+r}+B x^{\lambda_{1}}$, for some $A, B$, if we take the no-bubble conditions into account. Then, we determine $A, B, x_{1}^{*}, x_{0 R}$ employing the value-matching and the smooth-pasting conditions $E^{1}\left(x_{1}^{*}\right)=0, E_{x}^{1}\left(x_{1}^{*}\right)=0$, $E^{0}\left(x_{0 R}\right)=E^{1}\left(x_{0 R}\right)$ and $E_{x}^{0}\left(x_{0 R}\right)=E_{x}^{1}\left(x_{0 R}\right)$.

Part (b). Using the definition of $x_{i}^{*}(8)$ we can rewrite $F^{R}(x)$

$$
\begin{gathered}
F^{R}(x)=\left(1-\lambda_{0}\right) \frac{K}{r-\mu}\left(x-x_{0}^{*}\right)-\left(1-\lambda_{0}\right) \frac{K}{r+p_{1}-\mu}\left(x-x_{1}^{*}\right)+ \\
-\frac{\lambda_{0}-\lambda_{1}}{\lambda_{1}} \frac{K x_{1}^{*}}{r+p_{1}-\mu}\left[\left(\frac{x}{x_{1}^{*}}\right)^{\lambda_{1}}-1\right]
\end{gathered}
$$


and hence $F^{R}\left(x_{1}^{*}\right)<0$ if and only if $x_{1}^{*}<x_{0}^{*}$. Thus, engaging in a last resort gamble strategy is optimal (i.e. $x_{0 R}>x_{1}^{*}$ ) if and only if $x_{0}^{*}>x_{1}^{*}$. Note that $F^{R}\left(x_{0}^{*}\right)<0$ and consequently $x_{0 R}>x_{0}^{*}>x_{1}^{*}$

Increasing $C$ reduces the gap between $x_{0}^{*}$ and $x_{1}^{*}$ since

$$
\frac{\partial\left(x_{0}^{*}-x_{1}^{*}\right)}{\partial C}=-\frac{\lambda_{0}}{1-\lambda_{0}} \frac{1}{K} \frac{r-\mu}{r}+\frac{\lambda_{1}}{1-\lambda_{1}} \frac{1}{K} \frac{r+p_{1}-\mu}{r+p_{1}}<0
$$

Since for $C=r H$, Assumption 1 implies that $x_{1}^{*}<x_{0}^{*}$, and since, for $C \rightarrow \infty, x_{1}^{*}>x_{0}^{*}$, by continuity there exists a unique value of $C$ such that $x_{0}^{*}=x_{1}^{*}$. For each $C<\widehat{C}, x_{1}^{*}<x_{0}^{*}$ and thus $F^{R}\left(x_{1}^{*}\right)<0$ and as a consequence $x_{0 R}>x_{1}^{*}$, while for each $C \geq \widehat{C}, x_{1}^{*} \geq x_{0}^{*}$ and thus $F^{R}\left(x_{1}^{*}\right)>0$ and as a consequence $x_{0 R} \geq x_{1}^{*}$.

Proof of Proposition 4. The sign of the derivative of $\frac{\partial\left(x_{0}^{*}-x_{1}^{*}\right)}{\partial C}$ has already been proved in the proof of Proposition 3.

In this proof we calculate the sign of the derivative $\frac{\partial\left(x_{0 R}-x_{1}^{*}\right)}{\partial C}$. We rewrite $F^{R}\left(x_{0 R}\right)=0$ as

$$
\left(1-\lambda_{0}\right)\left(\frac{1}{r-\mu}-\frac{1}{r+p_{1}-\mu}\right)\left(x_{0 R}-x_{1}^{*}\right)=\left(1-\lambda_{0}\right) \frac{1}{r-\mu}\left(x_{0}^{*}-x_{1}^{*}\right)+g\left(x_{0 R}, x_{1}^{*}\right)
$$

where

$$
g\left(x_{0 R}, x_{1}^{*}\right)=\frac{x_{1}^{*}}{r+p_{1}-\mu} \frac{\lambda_{0}-\lambda_{1}}{\lambda_{1}}\left[\left(\frac{x_{0 R}}{x_{1}^{*}}\right)^{\lambda_{1}}-1\right]
$$

and where, since $x_{0 R}>x_{1}^{*}$ and $\lambda_{1}<1, g\left(x_{0 R}, x_{1}^{*}\right)>0$.

Let us define $L\left(x_{0 R}, x_{1}^{*}\right) \equiv \frac{\partial g\left(x_{0 R}, x_{1}^{*}\right)}{\partial x_{0 R}}+\frac{\partial g\left(x_{0 R}, x_{1}^{*}\right)}{\partial x_{1}^{*}}$. The following Lemma summarizes the properties of $L\left(x_{0 R}, x_{1}^{*}\right)$.

\section{Lemma A1.}

(i) $L\left(x_{1}^{*}, x_{1}^{*}\right)=0$; (ii) $L\left(x_{0 R}, x_{1}^{*}\right)$ is strictly increasing in $x_{0 R}$;

(iii) $\lim _{x_{0 R} \rightarrow \infty} L\left(x_{0 R}, x_{1}^{*}\right)=-\frac{1}{r+p_{1}-\mu}\left(\lambda_{0}-\lambda_{1}\right) \frac{1}{\lambda_{1}}$. 
Proof. The derivatives of $L\left(x_{0 R}, x_{1}^{*}\right)$ are

$$
\begin{gathered}
\frac{\partial g\left(x_{0 R}, x_{1}^{*}\right)}{\partial x_{0 R}}=\frac{1}{r+p_{1}-\mu}\left(\lambda_{0}-\lambda_{1}\right)\left(\frac{x_{0 R}}{x_{1}^{*}}\right)^{\lambda_{1}-1} \\
\frac{\partial g\left(x_{0 R}, x_{1}^{*}\right)}{\partial x_{1}^{*}}=\frac{1}{r+p_{1}-\mu} \frac{\lambda_{0}-\lambda_{1}}{\lambda_{1}}\left[\left(1-\lambda_{1}\right)\left(\frac{x_{0 R}}{x_{1}^{*}}\right)^{\lambda_{1}}-1\right]
\end{gathered}
$$

and thus

$$
L\left(x_{0 R}, x_{1}^{*}\right)=\frac{1}{r+p_{1}-\mu}\left(\lambda_{0}-\lambda_{1}\right)\left[\frac{1-\lambda_{1}}{\lambda_{1}}\left(\frac{x_{0 R}}{x_{1}^{*}}\right)^{\lambda_{1}}-\frac{1}{\lambda_{1}}+\left(\frac{x_{0 R}}{x_{1}^{*}}\right)^{\lambda_{1}-1}\right]
$$

(i) From (14) it is easy to see that $L\left(x_{1}^{*}, x_{1}^{*}\right)=0$.

(ii) Taking the derivative of (14) with respect to $x_{0 R}$ we obtain

$$
\frac{\partial L\left(x_{0 R}, x_{1}^{*}\right)}{\partial x_{0 R}} \approx\left(1-\lambda_{1}\right)\left(\frac{x_{0 R}}{x_{1}^{*}}\right)^{\lambda_{1}}+\left(\lambda_{1}-1\right)\left(\frac{x_{0 R}}{x_{1}^{*}}\right)^{\lambda_{1}-1}>0
$$

(iii) Since $\lambda_{1}<0$, it follows that $\lim _{x_{0 R} \rightarrow \infty} L\left(x_{0 R}, x_{1}^{*}\right)=-\frac{1}{r+p_{1}-\mu}\left(\lambda_{0}-\lambda_{1}\right) \frac{1}{\lambda_{1}}$.

From (11) we obtain $\frac{\partial\left(x_{0 R}-x_{1}^{*}\right)}{\partial C}$

$$
\begin{gathered}
\left(1-\lambda_{0}\right)\left(\frac{1}{r-\mu}-\frac{1}{r+p_{1}-\mu}\right) \frac{\partial\left(x_{0 R}-x_{1}^{*}\right)}{\partial C}=\left(1-\lambda_{0}\right) \frac{1}{r-\mu} \frac{\partial\left(x_{0}^{*}-x_{1}^{*}\right)}{\partial C}+ \\
+\frac{\partial g\left(x_{0 R}, x_{1}^{*}\right)}{\partial x_{0 R}} \frac{\partial x_{0 R}}{\partial C}+\frac{\partial g\left(x_{0 R}, x_{1}^{*}\right)}{\partial x_{1}^{*}} \frac{\partial x_{1}^{*}}{\partial C}
\end{gathered}
$$

Adding and subtracting $\frac{\partial g\left(x_{0 R}, x_{1}^{*}\right)}{\partial x_{0 R}} \frac{\partial x_{1}^{*}}{\partial C}$ on the left-hand-side of (15) and rearranging terms we obtain

$$
\frac{\partial\left(x_{0 R}-x_{1}^{*}\right)}{\partial C}=\frac{\left(1-\lambda_{0}\right) \frac{1}{r-\mu} \frac{\partial\left(x_{0}^{*}-x_{1}^{*}\right)}{\partial C}+L\left(x_{0 R}, x_{1}^{*}\right) \frac{\partial x_{1}^{*}}{\partial C}}{\left(1-\lambda_{0}\right)\left(\frac{1}{r-\mu}-\frac{1}{r+p_{1}-\mu}\right)-\frac{\partial g\left(x_{0 R}, x_{1}^{*}\right)}{\partial x_{0 R}}}
$$

In the following we show that the numerator as well as the denominator of the right-hand-side of (16) are positive.

We now proceed to prove that the numerator of (16) is negative. The first term of the numerator is negative (see the first part of this proof) while the second term, since $L\left(x_{0 R}, x_{1}^{*}\right) \geq 0$ and $\frac{\partial x_{1}^{*}}{\partial C}>0$, is positive. Since $L\left(x_{0 R}, x_{1}^{*}\right)$ is strictly increasing in $x_{0 R}$, a sufficient condition for the numerator to be negative is

$$
-\left(1-\lambda_{0}\right) \frac{1}{r-\mu} \frac{\partial\left(x_{0}^{*}-x_{1}^{*}\right)}{\partial C}>\frac{1}{r+p_{1}-\mu}\left(\lambda_{0}-\lambda_{1}\right) \frac{1}{\lambda_{1}} \frac{\partial x_{1}^{*}}{\partial C}
$$


which, after substituting the derivatives and simplifying terms, is equivalent to

$$
\left(1-\lambda_{0}\right) \frac{1}{r-\mu}\left(\frac{\lambda_{0}}{1-\lambda_{0}} \frac{r-\mu}{r}-\frac{\lambda_{1}}{1-\lambda_{1}} \frac{r+p_{1}-\mu}{r+p_{1}}\right)>\frac{\lambda_{0}-\lambda_{1}}{1-\lambda_{1}} \frac{1}{r+p_{1}}
$$

Rearranging further terms yields

$$
\lambda_{0}\left(\lambda_{1}-1\right) \mu p_{1}+\left(\lambda_{0}-\lambda_{1}\right) r p_{1}>0
$$

which is always true.

Next we show that the denominator of (16) is positive. Using (12) the numerator reads

$$
M\left(x_{0 R}, x_{1}^{*}\right) \equiv\left(1-\lambda_{0}\right)\left(\frac{1}{r-\mu}-\frac{1}{r+p_{1}-\mu}\right)-\frac{1}{r+p_{1}-\mu}\left(\lambda_{0}-\lambda_{1}\right)\left(\frac{x_{0 R}}{x_{1}^{*}}\right)^{\lambda_{1}-1}
$$

Note that $M\left(x_{0 R}, x_{1}^{*}\right)$ is strictly increasing in $x_{0 R}$ and

$$
\lim _{x_{0 R} \rightarrow \infty}\left(1-\lambda_{0}\right)\left(\frac{1}{r-\mu}-\frac{1}{r+p_{1}-\mu}\right)>0
$$

Thus, since $x_{0 R}>x_{1}^{*}$ it is sufficient to prove that $M\left(x_{1}^{*}, x_{1}^{*}\right)>0$, where $M\left(x_{1}^{*}, x_{1}^{*}\right)>0$ can be rewritten as

$$
\frac{r+p_{1}-\mu}{r-\mu}>\frac{1-\lambda_{1}}{1-\lambda_{0}}
$$

Subtracting $\mu$ from both sides of (4) we have

$$
\left(\lambda_{i} \frac{1}{2} \sigma^{2}+\mu\right)\left(\lambda_{i}-1\right)=r+p_{i}-\mu
$$

Note that the right-hand-side of this expression is positive valued by Assumption 1 (which implies that $\left.\lambda_{i} \frac{1}{2} \sigma^{2}+\mu<0\right)$. Substituting this last result into (18) we obtain

$$
\frac{\left(1-\lambda_{1}\right)\left(\lambda_{1} \frac{1}{2} \sigma^{2}+\mu\right)}{\left(1-\lambda_{0}\right)\left(\lambda_{0} \frac{1}{2} \sigma^{2}+\mu\right)}>\frac{1-\lambda_{1}}{1-\lambda_{0}}
$$

Simplifying and rearranging terms we obtain $-\lambda_{1}>-\lambda_{0}$, which is true.

Proof of Proposition 5. Under the risky debt assumption the value of the equity-holders' claim satisfies the following differential equation:

$$
r E^{i}=K x+\gamma^{i} K-f-C+\mu E_{x}^{i}+\frac{1}{2} \sigma^{2} E_{x x} x^{2}+p^{i}\left(-E^{i}\right)
$$


for $i=0,1,2$.

We assume that both gambling intensities are active and calculate the equity value and gamble and closure thresholds, and afterwards we show that this is true for sufficiently low coupon values (i.e. $C<\bar{C}$ ).

From (19), imposing value matching conditions $E^{2}\left(x_{0 L}\right)=E^{1}\left(x_{0 L}\right), E^{1}\left(x_{1 L}\right)=E^{0}\left(x_{1 L}\right)$ and $E^{0}\left(x_{2}\right)=0$ we obtain

$$
\begin{gathered}
E^{2}(x)=\frac{K x}{r+p_{2}-\mu}+\frac{\gamma_{2} K-C-f}{r+p_{2}}+ \\
+\left(-\frac{K x_{2}^{*}}{r+p_{2}-\mu}-\frac{\gamma_{2} K-C-f}{r+p_{2}}\right)\left(\frac{x}{x_{2}^{*}}\right)^{\lambda_{2}} \\
E^{1}(x)=\frac{K x}{r+p_{1}-\mu}+\frac{\gamma_{1} K-C-f}{r+p_{1}}+\left(\frac{K x_{1 L}}{r+p_{2}-\mu}+\frac{\gamma_{2} K-C-f}{r+p_{2}}-\frac{K x_{1 L}}{r+p_{1}-\mu}-\frac{\gamma_{1} K-C-f}{r+p_{1}}\right)\left(\frac{x}{x_{1 L}}\right)^{\lambda_{1}}+ \\
\left(-\frac{K x_{2}^{*}}{r+p_{2}-\mu}-\frac{\gamma_{2} K-C-f}{r+p_{2}}\right)\left(\frac{x_{1 L}}{x_{2}^{*}}\right)^{\lambda_{2}-\lambda_{1}}\left(\frac{x}{x_{2}^{*}}\right)^{\lambda_{1}} \\
E^{0}(x)=\frac{K x}{r-\mu}-\frac{C+f}{r}+\left(\frac{K x_{0 L}}{r+p_{1}-\mu}+\frac{\gamma_{1} K-C-f}{r+p_{1}}+\frac{C+f}{r}-\frac{K x_{0 L}}{r-\mu}\right)\left(\frac{x}{x_{0 L}}\right)^{\lambda_{0}}+ \\
\left(\frac{K x_{1 L}}{r+p_{2}-\mu}+\frac{\gamma_{2} K-C-f}{r+p_{2}}-\frac{K x_{1 L}}{r+p_{1}-\mu}-\frac{\gamma_{1} K-C-f}{r+p_{1}}\right)\left(\frac{x_{0 L}}{x_{1 L}}\right)^{\lambda_{1}-\lambda_{0}}\left(\frac{x}{x_{1 L}}\right)^{\lambda_{0}}+ \\
\left(-\frac{K x_{2}^{*}}{r+p_{2}-\mu}-\frac{\gamma_{2} K-C-f}{r+p_{2}}\right)\left(\frac{x_{1 L}}{x_{2}^{*}}\right)^{\lambda_{2}-\lambda_{1}}\left(\frac{x_{0 L}}{x_{2}^{*}}\right)^{\lambda_{1}-\lambda_{0}}\left(\frac{x}{x_{2}^{*}}\right)^{\lambda_{0}}
\end{gathered}
$$

where gambling thresholds $x_{1 L}$ and $x_{0 L}$ are obtained imposing smooth pasting conditions $E_{x}^{2}(x)=$ $E_{x}^{1}(x)$ and $E_{x}^{1}(x)=E_{x}^{0}(x), F^{1}(x)$ and $F^{0}(x)$ are defined as follows:

$$
\begin{gathered}
F^{1}(x)=K x\left(1-\lambda_{1}\right)\left(\frac{1}{r+p_{1}-\mu}-\frac{1}{r+p_{2}-\mu}\right)+\frac{\lambda_{1}-\lambda_{2}}{1-\lambda_{2}}\left(-\frac{\gamma_{2} K-C-f}{r+p_{2}}\right)\left(\frac{x}{x_{2}^{*}}\right)^{\lambda_{2}}+ \\
+\lambda_{1}\left(\frac{\gamma_{2} K-C-f}{r+p_{2}}-\frac{\gamma_{1} K-C-f}{r+p_{1}}\right)
\end{gathered}
$$

and

$$
\begin{gathered}
F^{0}(x)=K x\left(1-\lambda_{0}\right)\left(\frac{1}{r-\mu}-\frac{1}{r+p_{1}-\mu}\right)+\frac{\lambda_{0}-\lambda_{1}}{1-\lambda_{1}}\left(-\frac{\gamma_{2} K-C-f}{r+p_{2}}\right)\left(\frac{x_{1 L}}{x_{2}^{*}}\right)^{\lambda_{2}}\left(\frac{x}{x_{1 L}}\right)^{\lambda_{1}}+ \\
+\lambda_{0}\left(\frac{C+f}{r}+\frac{\gamma_{1} K-C-f}{r+p_{1}}\right)+\frac{\lambda_{0}-\lambda_{1}}{1-\lambda_{1}}\left(\frac{\gamma_{2} K-C-f}{r+p_{2}}-\frac{\gamma_{1} K-C-f}{r+p_{1}}\right)
\end{gathered}
$$

and closure threshold $x_{2}^{*}$ solve the smooth pasting condition $E_{x}^{2}(x)=0$.

In the following we show that $\bar{C}$ exists. In particular, we first show that Assumption 2 guarantees that as long as debt is risk-free the inequality $x_{0 L}>x_{1 L}>x_{2}^{*}$ holds and then we show that increasing riskiness of the debt value there exists a critical coupon value below which engaging in last resort gambling behavior with intensity 2 is optimal for some values of $x$, while above this threshold last resort gambling with intensity 2 is never optimal. 
Note first that Assumption 2 implies that, as long as debt is risk-free, $x_{0}^{*}>x_{1}^{*}>x_{2}^{*}$. We divide the proof into two parts: (a) $x_{1 L}>x_{2}^{*}$ and (b) $x_{0 L}>x_{1 L}$.

Part (a). $F^{1}(x)$ is a convex function of $x$. Thus, to prove that $x_{1 L}>x_{2}^{*}$ we show that $F^{1}\left(x_{2}^{*}\right)<0$. Using (8) we can rewrite $F^{1}(x)$ as

$$
F^{1}(x)=\left(1-\lambda_{1}\right) \frac{K}{r+p_{1}-\mu}\left(x-x_{1}^{*}\right)-\left(1-\lambda_{1}\right) \frac{K}{r+p_{2}-\mu}\left(x-x_{2}^{*}\right)-\frac{\lambda_{1}-\lambda_{2}}{\lambda_{2}} \frac{K x_{2}^{*}}{r+p_{2}-\mu}\left[\left(\frac{x}{x_{2}^{*}}\right)^{\lambda_{2}}-1\right]
$$

and hence $F^{1}\left(x_{2}^{*}\right) \leq 0$ if and only if $x_{1}^{*}>x_{2}^{*}$, which is satisfied by Assumption 2. Moreover, since $x_{1}^{*}>x_{2}^{*}$ and $\lambda_{2}<0$, from (20) it follows that $F^{1}\left(x_{1}^{*}\right)<0$. Hence, $x_{1 L}>x_{1}^{*}>x_{2}^{*}$. Thus, investing in the risky project 2 is optimal (i.e. $x_{1 L}>x_{2}^{*}$ ) if and only if $x_{1}^{*}>x_{2}^{*}$.

Part (b). To prove that $x_{0 L}>x_{1 L}$ holds for sufficiently large values of $\gamma_{1}$ we rewrite, using $(8), F^{0}(x)$ as

$$
\begin{aligned}
F^{0}(x)= & \left(1-\lambda_{0}\right) \frac{K}{r-\mu}\left(x-x_{0}^{*}\right)-\left(1-\lambda_{0}\right) \frac{K}{r+p_{1}-\mu}\left(x-x_{1}^{*}\right)+ \\
& -\frac{\lambda_{0}-\lambda_{1}}{1-\lambda_{1}} \frac{1-\lambda_{2}}{\lambda_{2}} \frac{K x_{2}^{*}}{r+p_{2}-\mu}\left[\left(\frac{x_{1 L}}{x_{2}^{*}}\right)^{\lambda_{2}}\left(\frac{x}{x_{1 L}}\right)^{\lambda_{1}}-1\right]
\end{aligned}
$$

Since by Assumption $2 x_{0}^{*}>x_{1}^{*}$ and $\left(\frac{x_{1 L}}{x_{2}^{*}}\right)^{\lambda_{2}}\left(\frac{x_{0}^{*}}{x_{1 L}}\right)^{\lambda_{1}}<1, F^{0}\left(x_{0}^{*}\right)<0$ and consequently $x_{0 L}>x_{0}^{*}$. Observe that there always exists a value of $\gamma_{1}$ such that $x_{1}^{*}=x_{2}^{*}$. In this case condition $F^{1}(x)=0$ yields $x_{1 L}=x_{1}^{*}$, while condition $F^{0}(x)=0$ yields $x_{0 L}>x_{0}^{*}$ and thus we obtain, $x_{0 L}>x_{0}^{*}>x_{1}^{*}=$ $x_{1 L}$. By continuity inequality $x_{0 L}>x_{1 L}$ holds for sufficiently large values of $\gamma_{1}$.

Note that Assumption 3 implies that $\frac{\partial}{\partial C}\left(x_{2}^{*}-x_{1}^{*}\right)>\frac{\partial}{\partial C}\left(x_{1}^{*}-x_{0}^{*}\right)$ and as a consequence there exists a $\bar{C}$ such that $x_{2}^{*}=x_{1}^{*}$ while $x_{0}^{*}>x_{1}^{*}$ and thus for $C>\bar{C}$ gambling intensity 2 is no longer optimal, while gambling intensity 1 remains optimal for some values of $x$ as stated in Proposition 3.

To compute $D(x)$, let us solve the following differential equation (9) for $i=0$ for $x>x_{0 L}, i=1$ for $x_{1 L}<x \leq x_{0 L}$ and $i=2$ for $x_{2}^{*}<x \leq x_{1 L}$. The general solution of (9) is $\frac{C+p_{i} H}{r+p_{i}}+L_{i} x^{\lambda_{i}}$ for some $L_{i}$, if we take the no-bubble condition into account. We determine $L_{2}$ employing the boundary condition $D^{2}\left(x_{2}^{*}\right)=H$ and $L_{1}$ and $L_{0}$ employing the value matching conditions $D^{2}\left(x_{1 L}\right)=$ 
$D^{1}\left(x_{1 L}\right)$ and $D^{1}\left(x_{0 L}\right)=D^{0}\left(x_{0 L}\right)$, respectively, yielding

$$
\begin{gathered}
D^{2}(x)=\frac{C+p_{2} H}{r+p_{2}}\left(1-\left(\frac{x}{x_{2}^{*}}\right)^{\lambda_{2}}\right)+H\left(\frac{x}{x_{2}^{*}}\right)^{\lambda_{2}} \\
D^{1}(x)=\frac{C+p_{1} H}{r+p_{1}}+\left(\frac{C+p_{2} H}{r+p_{2}}-\frac{C+p_{1} H}{r+p_{1}}\right)\left(\frac{x}{x_{1 L}}\right)^{\lambda_{1}}+\left(H-\frac{C+p_{2} H}{r+p_{2}}\right)\left(\frac{x_{1 L}}{x_{2}^{*}}\right)^{\lambda_{2}-\lambda_{1}}\left(\frac{x}{x_{2}^{*}}\right)^{\lambda_{1}} \\
D^{0}(x)=\frac{C}{r}+\left(\frac{C+p_{1} H}{r+p_{1}}-\frac{C}{r}\right)\left(\frac{x}{x_{0 L}}\right)^{\lambda_{0}} \\
+\left(\frac{C+p_{2} H}{r+p_{2}}-\frac{C+p_{1} H}{r+p_{1}}\right)\left(\frac{x_{0 L}}{x_{1 L}}\right)^{\lambda_{1}-\lambda_{0}}\left(\frac{x}{x_{1 L}}\right)^{\lambda_{0}}+\left(H-\frac{C+p_{2} H}{r+p_{2}}\right)\left(\frac{x_{1 L}}{x_{2}^{*}}\right)^{\lambda_{2}-\lambda_{1}}\left(\frac{x_{0 L}}{x_{2}^{*}}\right)^{\lambda_{1}-\lambda_{0}}\left(\frac{x}{x_{2}^{*}}\right)^{\lambda_{0}}
\end{gathered}
$$

